\title{
Erratum to: Individual and Institutional Productivity in Educational Psychology Journals from 2009 to 2014
}

\author{
Hannah Greenbaum ${ }^{1} \cdot$ Lisa Meyer $^{1} \cdot$ M Cecil Smith $^{1}$ • \\ Amanda Barber ${ }^{1} \cdot$ Heather Henderson $^{1} \cdot$ David Riel $^{1}$. \\ Daniel H. Robinson ${ }^{2}$
}

Published online: 28 December 2016

(C) Springer Science+Business Media New York 2016

\section{Erratum to: Educ Psychol Rev (2016) 28:215-223 DOI 10.1007/s10648-016-9360-8}

The authors wish to indicate the following corrections to the referenced article. Under Table 1,

- the value for Other articles for author Herbert Marsh which is 17 should be corrected to 72 .

- Sydney under column 2014 institution for author Andrew Martin should be corrected to New South Wales.

- Ben-Gurion under column 2014 institution for author Avi Kaplan should be corrected to Temple.

- Author name Alexandre Morin should be corrected to Alexandre J. S. Morin and its institution should be corrected to Australian Catholic.

Under Table 2,

- Sydney under column 2014 institution for author Andrew Martin should be corrected to New South Wales.

- Maryland under column 2014 institution for author Jeffrey Green should be corrected to North Carolina at Chapel Hill.

- Ben-Gurion under column 2014 institution for author Avi Kaplan should be corrected to Temple.

- Michigan under column 2014 institution for author Lisa Linnenbrink-Garcia should be corrected to Michigan State.

The corrected tables are shown on the following pages.

The authors regret this oversight.

The online version of the original article can be found at http:10.1007/s10648-016-9360-8.

Daniel H. Robinson

dan.robinson@austin.utexas.edu

1 West Virginia University, Morgantown, WV, USA

2 Learning Sciences, The University of Texas at Austin, Mail code G2100, Austin, TX 78713, USA 


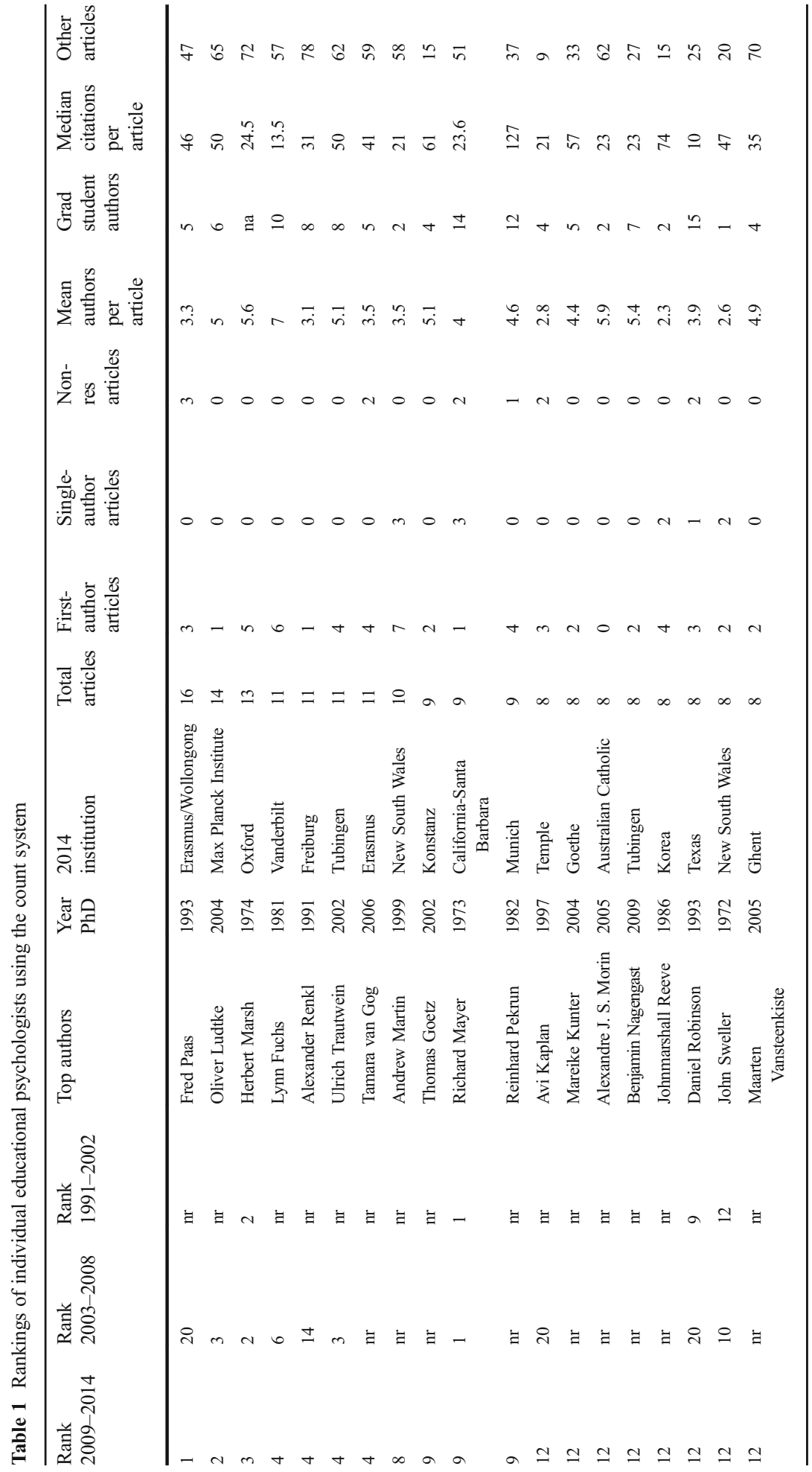




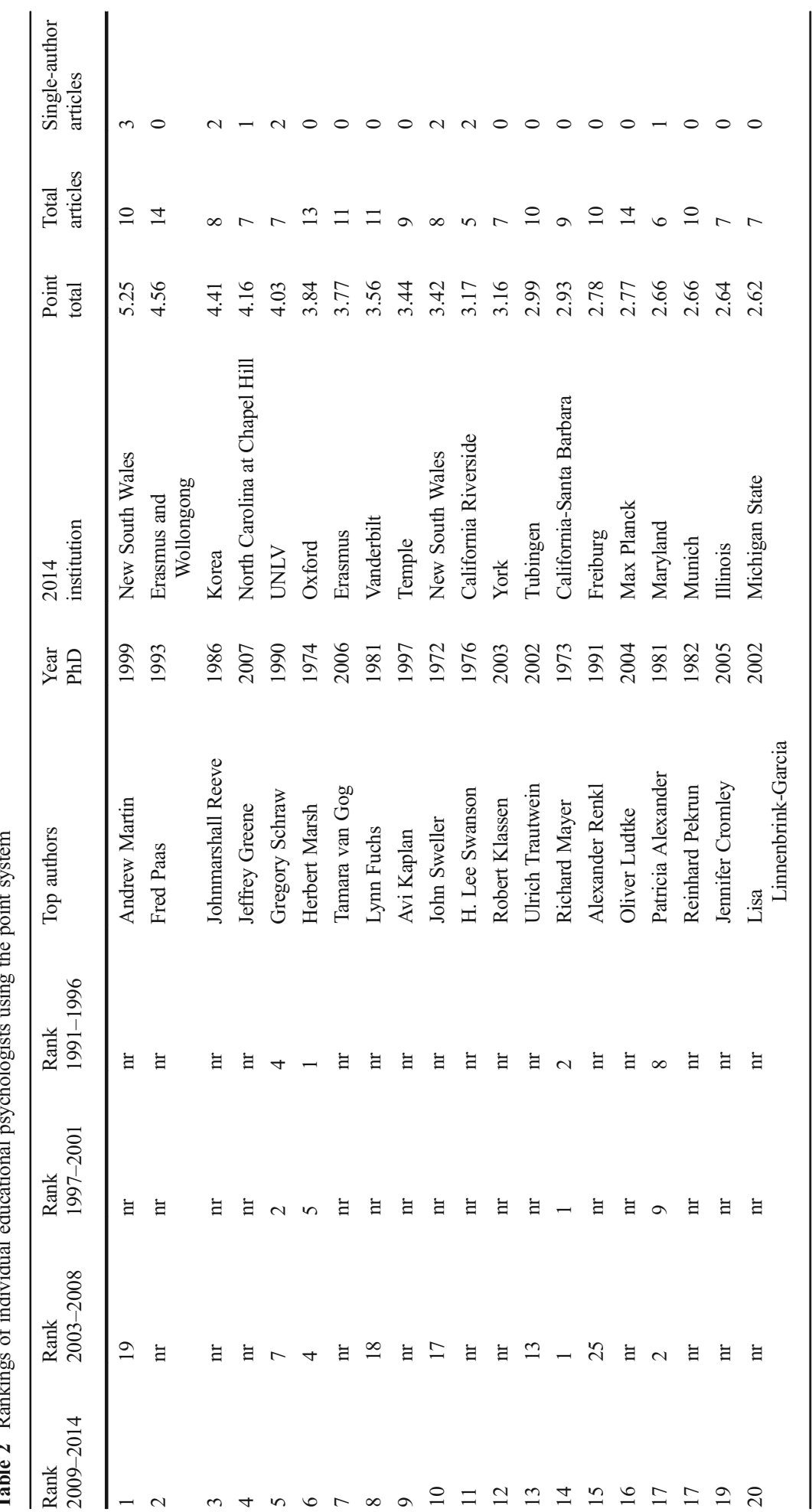

